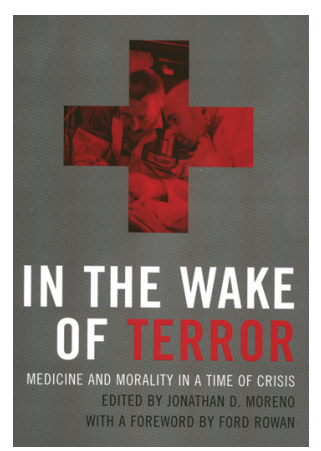

\title{
In the wake of terror: medicine and morality in a time of crisis
}

\author{
Jonathan D. Moreno, editor
}

The MIT Press, Cambridge, Massachusetts, USA. 2003. 264 pp. \$24.95. ISBN: 0-262-13428-4 (hardcover); 2004. 264 pp. \$14.95. ISBN: 0-262-63302-7 (paperback).

\section{Reviewed by Marshall E. Bloom}

E-mail:mbloom@niaid.nih.gov

Marshall Bloom is serving in his personal capacity.

A dozen essays on the contemporary ethical debate among advocates of public health measures, resource allocation, corporate responsibility, morality, civil liberties, individual rights, and governmental involvement are compiled in In the wake of terror: medicine and morality in a time of crisis. The essays discuss ethical considerations in public health and medical practice in a time of bioterror awareness.

The proposition being argued is that recent worries about bioterrorism demonstrate that "committed enemies of Western society ... have new capacity to strike terror and spread death" and that we as a society had better come to grips with the ethical as well as practical dilemmas of this new problem. The potential for catastrophic bioterror is palpable, but emerging problems, such as SARS, pose imminent risks and will also severely challenge our capacity to respond. Many of the same ethical considerations apply to both natural and human-caused calamities, but the recent focus on bioterror has brought these issues to prominence. Despite some annoying spelling and grammatical errors, the essays are well written and highly thought provoking.

The first section presents four essays on issues of public health and the declining acceptance of mandatory public health measures. There is a very pointed discourse about historical and potential collisions among individual rights, states' rights, human rights, federal author- ity, and "the greater good." Much of the material dances around the Model State Emergency Health Protection Act (MSEHPA), which was drafted in the fall of 2001 with federal assistance and was intended to provide a uniform template for updating existing state statutes dealing with health emergencies. The controversies that MSEHPA has generated are too complicated for this review, but the initial version was severely amended, and a number of parties distanced themselves from it. The diverse opinions make for lively reading and leave the reader appropriately conflicted and pondering the various points of view. To complicate matters further, the Health Insurance Portability and Accountability Act has piled on additional layers of confusion about these issues.

The section on resource allocation is much more pragmatic, dealing in large part with issues of triage and the inevitable scarcity of facilities, personnel, and supplies. A discussion about the relative merits of utilitarian versus egalitarian distribution of resources in response to an overwhelming bioterrorist attack points to the need for a "community of consent" and for a healthy dose of public involvement in planning efforts. The other essay in this section notes that a true bioterrorist catastrophe will probably compromise planning efforts for triage, overwhelm hospital capacity, and possibly make hospitals amplifiers of health hazards. The two essays on health care workers range rather wide- ly. Emergency health professionals are faced with issues of triage, scarcity, injustice, and inequity on a daily basis. This goes for workers in the US as well as those participating in emergencies and crises in other parts of the world. Some of the considerations here include whether such workers have a duty to face danger and how they cope with the "links forged among medicine, public health, law enforcement, and private industry in emergency assessment, response and preparation." Also, there is recognition of the "tension between the ideals of selfdetermination, voluntarism, privacy, justice, and the demands of sometimes secretive and nearly always hierarchical social institutions." These are highly personal essays that appear to reflect the direct experience of the authors, one of whom is an emergency care physician.

The piece on corporate motives and morality in the section entitled "Industry obligations" is particularly telling. It will be interesting to see if relevant corporate entities will rise above considerations of the bottom line and product liability as needs for new therapeutics, diagnostics, and vaccines develop.

"Research involving victims of terror," an essay in the final section, deals with the unique ethical considerations associated with doing clinical research following terror events. It suggests that standard regulations and protections for informed consent, privacy, etc., may be inadequate if subjects have suffered through severe episodes of terror. The last contribution to the volume raises the specter of genetically altered infectious agents as bioterror weapons and discusses how to balance the risks and benefits of research designed to define virulence factors. The scientific community is wrestling with these precise issues today.

This book reflects some very deep thinking about the limits of medical practice in a country newly anxious over terror. Although that anxiety, and those limits, are commonplace for many in the world, the essays serve to focus these concerns with a new immediacy. 